\title{
Mucopolysaccharidosis II, IV-A and VI: First Colombian Neuropsychological Characterization
}

\author{
Nolly Nataly Castañeda-lbáñez ${ }^{1}$ and María Rocio Acosta-Barreto,*
}

\author{
${ }^{1}$ San Buenaventura University, Calle 13 sur 8-34, Bogotá, Colombia \\ ${ }^{2}$ San Buenaventura University, Carrera 8 H 172-20, Bogotá, Colombia
}

\begin{abstract}
The Mucopolysaccharidosis [MPS] are a group of orphan or rare genetic diseases characterized by lysosomal storage disorders which are recognized by bone malformations and neuropsychological implications that have not been studied so far. For this reason, the first cross-sectional descriptive study of neuropsychological nature was conducted on variants of the disease, Hunter Syndrome [MPS II], Morquio A Syndrome [MPS IV A] and Maroteaux-Lamy syndrome [MPS VI] in 21 children and adolescents aged 3 to 19 years old, at the Colombian Association of Patients with Lysosomal Storage Diseases [ACOPEL, for its Spanish acronym] in Bogotá, Colombia. Results indicate that for the different types of MPS tested is not easy to make a neuropsychological characterization and generalize these results to other populations. However, MPS type II shows moderate to severe cognitive deficit with a compromise in psychomotor development. Morquio A presents average intelligence, and MPS type VI points to deficits partially related to sensory impairment, implying significant differences between them. It is important to continue carrying on this type of studies to achieve a better classification of these diseases according to their cognitive functioning from the neuropsychological perspective.
\end{abstract}

Keywords: Mucopolysaccharidosis, Hunter Syndrome, Morquio A Syndrome, Maroteaux-Lamy Syndrome, Neuropsychological characterization.

\section{INTRODUCTION}

The mucopolysaccharidosis [MPS] are a group of congenital metabolic diseases characterized by the presence of lysosomal deposits generated by the absence or deficiency of an enzyme responsible for releasing the useless deposits. This leads to an enzymatic lysosomal deficit or of certain membrane transport proteins responsible for the degradation of lipids and other molecules in the body [1, 2].

MPS diagnosis is made in the first instance by determining the presence of glycosaminoglycans (GAGs) in urine confirming the affectation, followed by the enzymatic blood test which determines the type of MPS by measuring the enzymatic activity of specific proteins $[3,4]$.

For all subtypes, as a result of the enzyme deficiency, GAG accumulation in cells of the body is produced, causing multisystem damage and revealing a phenotype characteristic of sufferers of the disease. Some signs and symptoms include short stature, joint pain and stiffness, claw hands, prominent organs, affected systems (respiratory, heart, viscera), corneal opacity, umbilical and / or inguinal hernia, carpal tunnel syndrome, hearing loss, thick lips and tongue, flat nasal bridge and mouth, frequent throat infections and

*Address correspondence to this author at the San Buenaventura University, Carrera 8H 172-20, Bogotá, Colombia; Tel: 573123062641 ;

E-mail: rocioacosta93@yahoo.com "noisy" breathing [4]. The manifestations in the central nervous system include cognitive deficits, learning disabilities, spinal deformities and spinal cord compression, hydrocephalus, mental retardation and dementia [5-7].

Hunter Syndrome or MPS type II is inherited in an simple autosomal recessive form, by mutation linked to $X$ chromosome, whereas asymptomatic carriers (heterozygotes) have a normal copy and a mutated one [8]. As a consequence of the mutation, there is a deficiency of the lysosomal enzyme Iduronate -2 sulfatase, leading to the progressive accumulation of GAG in almost all cell types, tissues and organs [2]. Death usually occurs in the second decade of life, although some patients have survived until the fifth or sixth decade. Until recently, there was no effective therapy for MPS II and care given was only palliative $[8,9]$. Currently, treatment consists of weekly intravenous infusions of Idursulfase that have shown to improve many of the signs, symptoms and general well-being of these patients.

Morquio A Syndrome, or MPS IV A type, is caused by deficiency of sulfatase $\mathrm{N}$-acetyl-galactosamine-6sulfate [10-12]. This syndrome manifests itself with difficulties such as skeletal chondrodysplasia, heart disease, corneal opacity, dwarfism and visceral involvement. Unlike other types of MPS, it is characterized by normal intelligence, a life expectancy of 20-30 years of age and a phenotype that varies from the classical form [13-15]. 
Table 1: Features Associated with the Mucopolysaccharidosis II, IV A and VI

\begin{tabular}{|c|c|c|c|}
\hline Clinical Features & Type II & Type IV A & Type VI \\
\hline Phenotype & Hunter Syndrome & Morquio A Syndrome & Maroteaux-Lamy Syndrome \\
\hline $\begin{array}{c}\text { Neurological Impairment } \\
\text { Mental Retardation } \\
\text { Airway Obstruction } \\
\text { Skeletal deformities } \\
\text { Limited joint mobility } \\
\text { Inguinal and umbilical hernias } \\
\text { Hip dysplasia } \\
\text { Hepatosplenomegaly } \\
\text { Sleep Apnea } \\
\text { Corneal opacity } \\
\text { Short stature } \\
\text { Claw hand } \\
\text { Heart Disease } \\
\text { Macroglossia } \\
\text { Hearing loss }\end{array}$ & $\begin{array}{c}+++ \\
+++ \\
+++ \\
+ \\
++ \\
+ \\
+ \\
+ \\
++ \\
+ \\
+ \\
+ \\
+ \\
+ \\
++ \\
++\end{array}$ & $\begin{array}{c}- \\
- \\
+ \\
++ \\
++ \\
+ \\
+ \\
+ \\
+ \\
+/- \\
++ \\
+ \\
+ \\
+/- \\
+\end{array}$ & $\begin{array}{c}+ \text { +++ } \\
+ \\
++ \\
+++ \\
++ \\
++ \\
++ \\
+ \\
++ \\
+++++ \\
++ \\
+++ \\
++ \\
+++ \\
++\end{array}$ \\
\hline Deficient enzyme & L-Iduronate-sulphatase & $\begin{array}{l}\text { Galactose-6- } \\
\text { Sulphatase }\end{array}$ & $\begin{array}{l}\text { Acetylgalactosamine 4- } \\
\text { Sulphatase }\end{array}$ \\
\hline Gene Location & $\mathrm{Xq28}$ & $16 q 24.3$ & $5 q 13-q 14$ \\
\hline
\end{tabular}

Absent, +/- Mild or absent, + Mild, ++ Moderate, +++ Severe.

The Maroteaux-Lamy Syndrome, MPS type VI, is a rapidly progressive multisystem lysosomal storage disorder in which ASB Arylsulfatase deficiency leads to storage of Dermatan Sulfate glycosaminoglycans in the tissues [16]. Patients with MPS VI have different levels of severity, with symptoms such as obstructive lung disease, cardiomyopathy, hepatosplenomegaly, corneal opacity, optic nerve atrophy, blindness, spinal instability, otitis media, hearing loss, dysplasia and short stature [17].

The following table shows the different features associated with the characteristic phenotype of these syndromes.

As for the clinical manifestations of MPS, these are determined by different enzyme defects that differ from each other, but with similar phenotypic characteristics [18]. For example, MPS III is always present with delay in psychomotor development and progressive neurological impairment, while this feature may or may not be present in MPS II and VII and is generally absent in MPS IV A and VI. Typical facial features are manifested in the first three years of age, and according to Wraith et al. [8] they are multisystemic and progressive diseases. Table 2 summarizes impairments reported in studies done so far.

The prognosis of MPS is variable depending on the age of onset of therapy and the rate of the disease progression. Neuropsychological interventions that may help preserve cognitive functioning of this type of diagnosis are unknown [16-18]. In addition, it should be noted that research studies related to brain damage in this type of disease are scarce. The literature has reported behavioral and genetic studies in animals with MPS [19, 20] but in humans there is little scientific research reported and this merely describes general characteristics of the central nervous system (CNS) by type of MPS [21]. Also, there is a lack of

Table 2: Nervous System Disorders

\begin{tabular}{|c|c|c|c|c|}
\hline $\begin{array}{c}\text { MPS } \\
\text { Type }\end{array}$ & $\begin{array}{c}\text { Psychomotor } \\
\text { Development Delay }\end{array}$ & $\begin{array}{c}\text { Neurological } \\
\text { Impairment }\end{array}$ & Spinal Cord Compression & Language \\
\hline \hline II & +++ & +++ & $+/-$ & +++ \\
\hline IV & $+/-$ & $+/-$ & +++ \\
\hline VI & $+/++$ & + & $++/+$ & + \\
+
\end{tabular}

- Absent, +/- Mild or absent, + Mild, ++ Moderate, +++ Severe. 
neuropsychological studies to identify cognitive functioning of sufferers of this disease, and in developing countries like Colombia there are also no official reports on this subject, as it has been reported by the Federación Colombiana de Enfermedades Raras [22]. Therefore, this study was proposed with the aim to carry out a neuropsychological characterization of children and adolescents with Mucopolysaccharidosis type II, IV A and VI, from the Colombian Association of Patients with Lysosomal Storage Diseases [ACOPEL, for its Spanish acronym] in Bogotá, Colombia.

\section{METHOD}

\section{Type of Study}

A cross-sectional descriptive study was carried out [23], in which data were collected in a single moment and time and processed with quantitative and qualitative analysis.

\section{Participants}

21 children and adolescents between the ages of 3 and 19 years living in the city of Bogotá, diagnosed with MPS types II, IV A and VI, and related to ACOPEL, a non-profit organization that is dedicated to contributing to the elimination of barriers ranging from diagnosis to treatment, with the aim of helping patients in finding solutions for their comprehensive treatment and providing the required assistance to these patients, their families, medical staff and health institutions.

The sample selection was made by means of an intentional non-probability sampling, bearing in mind that at the association only a certain type of patient was found. For type II, 6 participants were included, as well as for type IV A and 9 participants for type VI. Inclusion criteria were: having MPS type II, IV A and VI, being from and residing in the city of Bogotá. Exclusion criteria were: sensory and /or motor impairments, or being hospitalized. The variables to be analyzed were cognitive functions such as attention, memory, language, gnosis and praxis, executive behavior and school skills like reading, writing and arithmetic. The following table (Table 3 ) shows the distribution of participants by age.

\section{Instruments: Neuropsychological Assessment of Children [ENI, for its Spanish acronym]}

This battery assesses the neuropsychological development of children. It comprises 12 basic neuropsychological assessment processes: Constructional skills, Memory, Language, Calculation, Attention, Metalinguistic skills, Perception, Spatial skills and Executive functions, to assess children from 5 to 16 years old [24-26].

\section{K-BIT}

The Kaufman Brief Intelligence Test covers an age range from 4 to 90 years old. It measures verbal intelligence (Vocabulary) and nonverbal (Matrices), using two subtests in children, adolescents and adults. The Spanish adaptation was used for this study, with reliability coefficients ranging from 0.80 to $0.90[27,28]$.

\section{Go / No-Go}

Used to assess executive processes in children and adolescents such as inhibition, immediate response, the ability to suppress thoughts and control their behavior. The task consists of presenting a stimulus to patients whose characteristic is dichotomous, doing / not-doing and their response is limited to only choosing between two options [29]. These stimuli are visual and they are presented through a laptop [30].

\section{Griffiths Development Scale}

This scale is formed by six subscales: locomotor, personal/ social, hearing / language, hand / eye coordination, and performance. For children ages 3 and up a subscale of practical reasoning has been added [31]. It was used to assess participants with MPS type II, due to their characteristics of psychomotor

Table 3: Comparison between Age and Type of MPS II, IV A and VI

\begin{tabular}{|c|c|c|c|c|}
\hline \multirow{2}{*}{ MPS Type } & \multicolumn{3}{|c|}{ Age } \\
\cline { 2 - 5 } & Median & SD & Maximum & 10 \\
\hline II & 8 & 1.8 & 12 & 3 \\
\hline \hline IV & 9 & 2.5 & 19 & 9 \\
\hline VI & 14 & 3.6 & & 9 \\
\hline
\end{tabular}

Standard Deviation: DS 
development. Studies have demonstrated the discriminative validity in terms of test sensitivity to the effects of prematurity, malnutrition and stimulation programs. The reliability of the test is expected to increase with respect to the estimates found in the original version.

\section{Procedure}

\section{Phase 1}

Selection of the sample. Contact with the association was made, the research proposal was presented, signatures of informed consents were obtained and verification of inclusion and exclusion criteria was carried out.

\section{Phase 2}

Application of the assessment protocol consisting of tests and batteries to assess cognitive functions such as attention, memory, language, calculation, arithmetic, gnosis, praxis, executive behavior and school skills. In participants with MPS type VI, because of their chronic corneal opacity, they were not able to make a proper visual tracking and understand in a clear and precise manner the incentives that were given to them. Therefore, it was necessary to modify some subtests of the ENI, such as Reading, Quantities Management and Written Calculation, by increasing the size of the stimuli.

\section{Phase 3}

Analysis of results and preparation of documents: the data obtained for each of the participants were compiled in order to carry out the individual neuropsychological characterization and deliver the report. With each of the findings of the individual assessment process the tabulation of the information obtained by the different types of MPS was made to accomplish a description and identification of each type of MPS intergroup and intra-group, respectively.

\section{Ethical Considerations}

The study fulfilled the research requirements specified in the Code of Ethics and Bioethics of Psychology, Act 23 of 1982 on copyright and intellectual property [32], Act 1090-060906 of 2006 [33], Act 1392 of 2010 [34], which state that it is of

Table 4: Scores on Griffiths Developmental Scale for MPS Type II

\begin{tabular}{|c|c|c|c|c|}
\hline Subscales & \multicolumn{3}{|c|}{ Ratings } \\
\cline { 2 - 5 } & ${ }^{*} \mathbf{M}$ & ${ }^{*}$ SD & ${ }^{*} \mathbf{M x}$ & 33 \\
\hline \hline Locomotion & 27 & 10 & 25 & 10 \\
\hline Personal / Social & 14 & 6.3 & 7 & 11 \\
\hline Hearing / Language & 7 & 0.5 & 19 & 11 \\
\hline Eye-hand coordination & 16 & 3.6 & 20 & 11 \\
\hline Execution & 18 & 3.9 & \\
\hline
\end{tabular}

Median: M, Standard Deviation: DS, Maximum: Mx, Minimum: Mn

Table 5: Scores on K-BIT and Go / No-Go for Type IV A and VI

\begin{tabular}{|c|c|c|c|c|c|c|c|c|c|c|c|c|}
\hline \multirow{3}{*}{$\begin{array}{l}\text { MPS } \\
\text { Type }\end{array}$} & \multicolumn{12}{|c|}{ K-BIT } \\
\hline & \multicolumn{4}{|c|}{ Vocabulary } & \multicolumn{4}{|c|}{ Matrices } & \multicolumn{4}{|c|}{ IQ Compound } \\
\hline & $\mathbf{M}$ & SD & Mx & Mn & M & SD & Mx & $M n$ & $\mathbf{M}$ & SD & Mx & Mn \\
\hline IV A & 37 & 8.5 & 30 & 47 & 61 & 7.5 & 55 & 70 & 47 & 7.5 & 34 & 47 \\
\hline \multirow[t]{4}{*}{$\mathrm{VI}$} & 14 & 13.5 & 7 & 42 & 30 & 14.8 & 1 & 39 & 13 & 9.9 & 2 & 29 \\
\hline & \multicolumn{12}{|c|}{ Go-No/Go } \\
\hline & & \multicolumn{4}{|c|}{ Task 1} & & & \multicolumn{4}{|c|}{ Task 2} & \\
\hline & & M & SD & $\mathrm{Mx}$ & $\mathrm{Mn}$ & & & $\mathrm{M}$ & SD & $\mathrm{Mx}$ & $\mathrm{Mn}$ & \\
\hline IV A & & 92 & 7.5 & 85 & 100 & & & 91 & 11.8 & 98 & 75 & \\
\hline VI & & 100 & 10.7 & 77 & 100 & & & 92 & 12.7 & 100 & 69 & \\
\hline
\end{tabular}

Median: M, Standard Deviation: DS, Maximum: Mx, Minimum: Mn. 
national interest to provide attention and preferential treatment to people with rare or orphan diseases, and Mental Health Act 1616 of 2013 [35] which guarantees the right to mental health, through promotion and prevention with comprehensive care.

\section{RESULTS}

Results were analyzed based on performance on neuropsychological tests, cognitive function and school skills. The percentile range was used for the description of these results since all scores are based on a maximum of 100 points and a minimum of 0 for the final measurement. Two standard deviations above and two below were taken into account to define the normal range. The statistical program SPSS version 21.0 for clustering of data, analysis and corresponding description was used. Results are shown In Tables 4 to 6.

\section{Qualitative Description}

Due to the cognitive and neuro-anatomical features of the participants with MPS II, Table 4 shows that for this group it was necessary to use another measurement that could equally describe the cognitive functioning of these males. For the atypical cases of this type of MPS - there were two of them- the protocol including ENI, K-BIT and Go-No/Go was administered.

The performance of participants with MPS type II was similar to that of children with Type $\mathrm{VI}$ and it is noteworthy that according to Giugliani et al. [36] they would belong to the atypical cases found in the literature about the phenotype and neurological development of Hunter Syndrome.

It is important to add that the older the age of the participants, further deterioration in cognitive abilities was found. Locomotor and performance skills are maintained over time, but they show a progressive decline on the hearing /language subscales.

As shown in Table 3, when comparing MPS IV A with MPS VI it is found that the median of age for these groups is nine and fourteen years, respectively, which would show a relationship with performances in school skills tests presented in Table 6 where medians closer to normal are typical of MPS type IV A, revealing deterioration as participants advance in age and school grade.

Regarding the performances on I.Q. of K-BIT, participants of Type IV A proved to have near average intelligence in relation to the data in a central position given by the median according to the test scales, and a low or low-normal performance for type VI. It can be observed that in both MPS groups, scores tend to be higher for Matrices which reflect the capacity for abstraction, analysis and problem solving in this population.

Table 5 shows the percentiles obtained on K-BIT and Go / No-Go for MPS types IV A and VI, identifying the diseases' achievement and their performances on the subtests. In Go-No / Go, both types of MPS had a good performance. Percentiles show a properly performed test indicating that the process of consolidation of executive behaviors has not been interrupted by factors associated to the diagnosis or by a cognitive deficit. MPS VI shows the highest scores in Task 1 and Task 2 which may be an indication that with increasing age, the greater will be the consolidation of the processes in terms of response inhibition, impulsivity and assertiveness after giving instructions for a task.

A general measure of cognitive functioning of these patients that can provide a better neuropsychological characterization is the ENI, which describes cognitive functioning within expected ranges for MPS type IV A but within low ranges for Type VI. Table 6 shows the medians and presents each of the domains assessed with their respective subtests, pointing out that Perception, Spatial skills and Attention are significantly low for Type $\mathrm{VI}$, so much so that it is not possible to score subtests as Visual Attention in order to carry out a comparative quantitative analysis with the other types of MPS.

In Table 6, the spaces where there is no score indicate that it was not possible to assess the subtest or that the scores obtained were not enough so that they could be placed in a percentile rank.

The meta-linguistic skills of Type IV A are in a lownormal percentile, the same as spatial skills. This can be due to the relationship between age and school learning processes that are not still consolidated in this population, and to the lack of appropriation of concepts such as right-left differentiation. MPS VI shares the same condition with respect to spatial skills, but low scores on auditory and visual perception add to poor performance. Certain abilities such as Constructional skills with chopsticks, meta-linguistic skills, auditory attention -despite factors associated with hearing loss in this type of MPS- and conceptual skills are found within the normal range. 
Table 6: Scores on NAC for MPS Type IV A and VI

\begin{tabular}{|c|c|c|c|c|c|c|c|c|}
\hline \multirow[t]{2}{*}{ Subscales } & \multicolumn{4}{|c|}{ MPS IV A } & \multicolumn{4}{|c|}{ MPS VI } \\
\hline & M & SD & Mx & Mn & $\mathbf{M}$ & SD & Mx & Mn \\
\hline Graph skills & 75 & 17.6 & 84 & 50 & 16 & 23.5 & 63 & 5 \\
\hline Delayed verbal memory & 37 & 7.5 & 50 & 37 & 16 & 8.5 & 26 & 2 \\
\hline Delayed visual memory & 84 & 12.1 & 99 & 75 & 9 & 25.8 & 50 & 0 \\
\hline Visual Perception & 26 & 13.8 & 50 & 26 & 2 & 37.9 & 84 & 0 \\
\hline Language: comprehension & 15 & 14.4 & 75 & 50 & 16 & 29.4 & 75 & 2 \\
\hline Metalinguistic skills & - & - & - & - & 26 & 18.4 & 50 & 0 \\
\hline Spatial skills & - & - & - & - & 1 & 2 & 5 & 0 \\
\hline Visual attention & 9 & 7.5 & 16 & 1 & - & - & - & - \\
\hline Auditory attention & 84 & 14.5 & 91 & 63 & 50 & 28.4 & 75 & 1 \\
\hline Conceptual skills & 84 & 4 & 91 & 84 & 26 & 30.7 & 75 & 16 \\
\hline Verbal fluency & 16 & 14.5 & 37 & 9 & 16 & 17.1 & 50 & 9 \\
\hline Correct designs & 63 & 6.9 & 75 & 63 & 37 & 14.2 & 63 & 37 \\
\hline Movements performed & 84 & 5.1 & 84 & 75 & 50 & 33.7 & 84 & 9 \\
\hline Minimum movements & 84 & 4 & 91 & 84 & 16 & 34.6 & 84 & 5 \\
\hline Reading accuracy & 16 & 16.2 & 37 & 5 & - & - & - & - \\
\hline Reading comprehension & 75 & 21.9 & 75 & 37 & 16 & 29.6 & 75 & 2 \\
\hline Reading speed & 0 & 15 & 26 & 0 & 0 & 7.1 & 16 & 0 \\
\hline Writing precision & 63 & 34.8 & 84 & 16 & 16 & 29.9 & 75 & 2 \\
\hline Narrative composition & 37 & 29 & 63 & 5 & 16 & 23.8 & 63 & 2 \\
\hline Writing speed & 26 & 19 & 37 & 0 & - & - & - & - \\
\hline Count & 75 & 10.5 & 84 & 63 & 63 & 28.3 & 84 & 16 \\
\hline Handling numeric & 63 & 33.4 & 63 & 5 & 0 & 2.7 & 5 & 0 \\
\hline Calculation & 37 & 23.5 & 63 & 16 & 16 & 18 & 37 & 0 \\
\hline Logical Reasoning & 84 & 4 & 91 & 84 & 50 & 26.3 & 84 & 16 \\
\hline
\end{tabular}

NAC: Neuropsychological Assessment of Children, Median: M, Standard Deviation: DS, Maximum: Mx, Minimum: Mn. 
Similarly, Table 6 shows difficulties in Visual Perception, Language Comprehension and Visual Attention for Type IV A corresponding to a borderline cognitive functioning. Memory coding processes for both types of MPS IV A and VI go hand in hand with each sensory channel assessed, that is to say, each MPS presents a performance on par via visual and auditory channels for the consolidation of information, but in the long run both channels are diminished so the percentiles show a loss of information in recall although they are within the expected ranges for age and level of schooling.

The executive behavior of the majority of this population is preserved as shown on Tasks Go / No-Go in Table 2, where percentiles are in accordance with the expected, not only in terms of normality but in terms of age and schooling. Performances on Verbal Fluency and Graphic Fluency, shown in Table 6, are similar in both types of MPS within normal parameters. However, some features differ among the types of MPS in performances that have to do with the inability to maintain the principle and percentage of perseverant responses, factors that may be associated with the age of Type IV A participants so they might score lower than their peers of Type VI.

Deficits on Spatial skills mentioned above as an impaired function in type $\mathrm{VI}$ are reflected in the difficulty performing visuospatial type associations, which does not occur in Type IV A. On functions that deal with planning, organization and percentage of correct responses, participants with Morquio A Syndrome score within a normal range surpassing those of Type VI who apparently presented difficulties in performance times on the subtests.

To complete the description of the results, school abilities assessed with the ENI Battery are described in Table 6. These show incomplete data because most participants with Morquio A have not yet formally started school so it was not possible to assess some processes such as reading accuracy, and Type VI children and adolescents show impairment in visual tracking and focusing power as well as hearing loss, which made it difficult to measure these skills.

Some subtests like Reading Comprehension are within the normal range for Type IV A, while Type VI shows scores ranging from low to normal with borderline intelligence, considering age and schooling level, and indicating impairment both in comprehensive and expressive language (with the exception of repetition). It has been found that participants with Morquio A show percentile medians consistent with the expected for age and school level in Mathematics or Arithmetic skills, which are located above those of participants with Type VI, who showed fluctuating scores, thus placing the disease within a borderline or low normal range.

In various tests and neuropsychological tasks such as ENI, the K-BIT and Go-No / Go, comparing two groups IV and VI statistical Mann-Whitney was used; They found no differences regarding age (MannWhitney $=7.00 ; p=0.12$ ); since it is correlated only 9 of the 45 variables assessed; Executive Function (UMann-Whitney $=15 ; p=0.86$ ) or constructional skills (U-Mann; no differences in scores on the scales Perception ( $p=0.73-$ Mann-Whitney $U=14$ ) met Whitney $=14 ; p=0.73$ ) and in terms of gender differences in spatial skills, conceptual skills and perceptual, among other found. A clinical and descriptive level IVA Morquio major difficulties in constructional tests and Maroteaux-Lamy in visual, auditory and constructional gnosias with cognitive performance below expectations. Executive function is preserved for both types of MPS. In conclusion, the kind of syndrome (in this case VI and IV A) does not affect the execution of certain tasks, or performance in certain scales statistically but clinically descriptive, show neuropsychological differences between groups.

\section{DISCUSSION}

According to the results obtained, there is a clear difference between MPS II and MPS IV A and VI whereby each participant has a basic diagnosis, but with notable differences found between MPS II and the other types of the disease, which only allowed the neuropsychological characterization through descriptions and identification of performance on the different cognitive functions studied, in addition to not having significant statistical measures to make a reliable quantitative analysis.

MPS II presents a marked deterioration at neurological level and delayed psychomotor development, coinciding with reports like that by Shah, Mahal \& Sharma [9], while MPS IV A and VI have different characteristics. Due to the absence of language, eye contact and communicative intent it was not possible to assess Type II with ENI and K-BIT, and therefore it was necessary to use the Griffiths Development Scale as a way to measure the relationship between chronological and mental age, 
which shows a cognitive functioning according to the performance that these children were able to show. Meanwhile, MPS IV A and VI responded positively to ENI, K-BIT and Go / No-Go, so it was not necessary to use that developmental scale to assess them.

No sex identifications were made for this study since there is a larger population of men than of women. However, in some performances of Type II and Type IV A, girls showed the best results, which would make it necessary to contrast these findings in further research with similar samples, in relation to data described in studies and theories on differential cognitive functioning of men and women and a possible differential progression of the disease.

The study corroborates literature findings in terms of the presence of moderate to severe cognitive deficit in MPS type II. Nevertheless, there are atypical cases of any disease or an exception to the rule, and that fact applies to this MPS in two cases, one of a child and other of a teenager who have been diagnosed with the disease but who cognitively show a performance within the expected limits in relation to the other types of MPS [37].

According to demographic and schooling data, it has been found that children and adolescents who have been out of school or have dropped out of it show low performance on the ENI subtests. In this regard, performance of some of the participants with MPS Type VI and Type IV on school skills surpasses that of children out of school by almost $50 \%$, which could indicate the need to describe possible relationships of these conditions in future studies.

MPS type IV A presents average neuropsychological characteristics as expected for their age and schooling [14]. MPS Type VI for his part was able to respond to the exercises on each of the subtests used, although showing deficits on processing speed, reading / writing and visual tracking.

The characterization shows both genetic and cognitive heterogeneity regarding performance on each of the subtests, so it is difficult to generalize this study to other populations. It is necessary to increase the number of descriptive studies to identify neuropsychological profiles of this disease, not only for the sake of the medical and genetic fields in general, but as a contribution to the Neuropsychological discipline, and thus being able to continue carrying on comparative and analytical studies. In Colombia, no research about brain damage in these diseases has been reported so far. There are organizations like ACOPEL which are responsible for providing all possible psychosocial support to both patients and their families through joint work with neurologists and associated laboratories for the provision of the patients' medication.

It is not unknown that studies like these have several limitations. It is not possible to generalize this characterization to all people suffering from MPS and much less to the different types not included in this study. However, a preliminary approach already exists for undertaking further research and carrying out other neuropsychological characterizations under a guideline and a more comprehensive and analytical view of their cognitive functioning. It would also be important to take into account issues such as gender, race, socio economic status and level of schooling in order to understand the possible deterioration in these patients. Nevertheless, since these syndromes are associated with a common phenotype it might not be still sufficient to achieve this understanding.

Limitations may also be associated with the fact of not being able to perform neuropsychological profiles of the disease in the future. Heterogeneity might be so great that it would not even be possible to cover a sufficiently significant population as to determine a profile on a single type of MPS. However, it is still an unexplored field for the discipline where there is a long way to go. The aim of this research is to lay the foundations to initiate further studies and thus over time break down such limitations hand in hand with multidisciplinary work.

As for the instruments used, it is clear that ENI is the most sensitive test battery for identifying and describing the possible deficits and skills on this type of diseases. Due to its easy application and the different cognitive components of this battery, it is possible to determine a more precise cognitive functioning which allows a characterization that best fits what is observed and measured during performances.

It has been taken into account that variability, especially in age, may have influenced the results obtained and particularly regarding a description by gender and decade of life. However, it is possible to extrapolate these studies to adult population by adjusting the type of instruments to suit the sensitivity of the sample and characteristic features of the disease. For children and young people, a high 
reliability was observed with the instruments used in this study. Therefore, it is suggested that the same instruments continue being used for future research with some changes in stimulus size for some ENI subtests such as Reading on School Skills, Quantity management and Written Calculation.

In the assessment process, it is possible that the cognitive deficit that is manifested in MPS Type VI might not be caused by a cognitive impairment as such or a malfunction of its CNS, considering that in the cases assessed sensory perceptual limitations related to the visual and auditory channels were observed which would not allow to differentiate whether the performance in each of the subtests is precisely due to a cognitive deficit or rather to a sensory limitation. This would require carrying out studies from the psychological realm that can provide guidance for further work and use neuropsychological batteries or validated tests that support the processes assessed.

Likewise, it is considered important to enhance multidisciplinary work with other professionals such as optometrists and speech therapists who can work hand in hand with neuropsychologists to be able to perform a more detailed analysis of that sensory perceptual deficit shown by subjects with MPS Type VI.

The contribution from this research to ACOPEL would be related to the generation of new strategies for prevention, promotion and intervention of future pathologies in the brain, if these are assessed, diagnosed and treated on time by a multidisciplinary team, considering that neurological, genetic and medical studies where clinical manifestations of CNS in MPS are mentioned can nurture this kind of descriptive studies. Clinics and rehabilitation centers may rely both on their experience and the profiles found in order to work towards these diseases. For Colombia, it could be a baseline for neuropsychological assessment, diagnosis and intervention processes with orphan and lysosomal storage diseases.

It also contributes to the academy with new knowledge about such disorders and rare diseases which have been poorly studied. The characterization of this population will allow a better understanding of their cognitive functioning and contribute to an early prevention of school dropout, thus increasing functionality in children and adolescents, favoring their occupational guidance toward a particular task and improving their quality of life.
Due to the impact generated by the study on this population and on different organizations involved in psychosocial support, the motivation to continue this type of study has increased. Being able to perform an adult characterization and obtain a measure of their cognitive functioning could lead in the future to estimate longevity of people affected by these diseases and generate ongoing supportive care strategies for maintaining their cognitive function. Progress of each of these processes and their stimulation could generate a positive impact on these patients improving their behavior, emotions, and daily functioning.

The management of these patients with Mucopolysaccharidosis depends on the identification, understanding and treatment of its multisystem manifestations, including support measures, which should be part of the regular multidisciplinary care of these patients and their specific therapies. There is evidence that early detection and treatment of patients possibly through assessment at school entry age can contribute to a better prognosis. A definite cure could perhaps be achieved through gene therapy, but that moment may still take some time to arrive so it is necessary to provide, from Neuropsychology, other forms of assessment, prevention and cognitive stimulation.

\section{ACKNOWLEDGMENTS}

Thanks to ACOPEL for provide the space, the human resources and the population to make this research a beginning of something new in Neuropsychology in Colombia. It is the first step to continue a big labor.

\section{REFERENCES}

[1] Campos LE, Pérez V, Villavicencio A, González M. Hallazgos oculares en niños con mucopolisacaridosis. Revista Médica del Instituto Mexicano del Seguro Social 2012; 50(5): 523-8.

[2] Hamano K, Hayashi M, Shioda K, Fukatsu R, Mizutani S. Mechanisms of neurodegeneration in Mucopolysaccharidosis II and IIIB: analysis of human brain tissue. Acta Neuropathologica 2008; 115: 547-59.

\section{http://dx.doi.org/10.1007/s00401-007-0325-3}

[3] Kloska A, Jakóbkiewicz-Banecka J, Narajczyk M, BaneckaMajkutewicz Z, Węgrzyn G. Effects of flavonoids on glycosaminoglycan synthesis: implications for substrate reduction therapy in Sanfilippo disease and other mucopolysaccharidoses. Metabolic Brain Disease 2011; 26: 1-8.

http://dx.doi.org/10.1007/s11011-011-9233-2

[4] Maceira MC, Atienza G. Detección precoz de mucopolisacaridosis y oligosacaridosis en el período neonatal mediante cribado poblacional. Revisión sistemática 2006. Madrid, España: Ministerio de Sanidad y Consumo. Avalia-t № 2006/08. ISBN: 978-84-95463-46-3 
[5] Cimaz $\mathrm{R}$, et al. Joint contractures in the absence of inflammation may indicate Mucopolysaccharidosis. Pediatric Rheumatology 2009; 7(18). http://dx.doi.org/10.1186/1546-0096-7-18

[6] Pan D, Sciascia A, Vorhees C, Williams M. Progression of multiple behavioral deficits with various age of onset in a murine model of Hurler Syndrome. Brain Research 2009; 1188: 241-53.

http://dx.doi.org/10.1016/.j.brainres.2007.10.036

[7] Walker $\mathrm{R}$, et al. Anesthesia and airway management in Mucopolysaccharidosis. Journal of Inherited Metabolic Disease 2013; 36: 211-19. http://dx.doi.org/10.1007/s10545-012-9563-1

[8] Wraith J, et al. Mucopolysaccharidosis type II (Hunter syndrome): A clinical review and recommendations for treatment in the era of enzyme replacement therapy. European Journal of Pediatrics 2008; 167: 267-77. http://dx.doi.org/10.1007/s00431-007-0635-4

[9] Shah G, Mahal T, Sharma S. A typical clinical presentation of Mucopolysaccharidosis type II (Hunter syndrome): a case report. Journal of Medical Case Reports 2010; 154(4): 1-4. http://dx.doi.org/10.1186/1752-1947-4-154

[10] Algahim M, Almassi GH. Current and emerging management options for patients with Morquio A syndrome. Therapeutics and Clinical Risk Managements 2013; 9: 45-53. http://dx.doi.org/10.2147/TCRM.S24771

[11] Khedhiri S, Chkioua L, Ferchichi S, Miled A., Laradi S. Polymorphisms in Tunisian patients with $\mathrm{N}$ acetylgalactosamine-6-sulfate sulfatase gene deficiency: Implication in Morquio A disease. Diagnostic Pathology 2011; 6(11): 1-5. http://dx.doi.org/10.1186/1746-1596-6-11

[12] Tomatsu, et al. Enhancement of Drug Delivery: Enzyme replacement Therapy for Murine Morquio a Syndrome. The American Society of Gene \& Cell Therapy 2010; 18(6): 10941102. http://dx.doi.org/10.1038/mt.2010.32

[13] Jurkiewicz E, Marcinska B, Nowacka J, Dobrzanska A. Clinical and radiological pictures of two newborn babies with manifestations of chondrodysplasia punctata and review of available literature. Polish Journal of Radiology 2013; 78(2): 57-64.

http://dx.doi.org/10.12659/PJR.883947

[14] Kubaski $F$, et al. Identification of a novel missense mutation in Brazilian patient with a severe form of Mucopolysaccharidosis type IVA. Gene 2013; 517: 112-115. http://dx.doi.org/10.1016/j.gene.2012.12.100

[15] Tomatsu S, Montaño A, Oikawa H. Mucopolysaccharidosis type IVA (Morquio A disease): clinical review and current treatment: a special review. Current Pharmaceutical Biotechnology 2011; 12(6): 931-945.

http://dx.doi.org/10.2174/138920111795542615

[16] Brands M, et al. Mucopolysaccharidosis type VI phenotypesgenotypes and antibody response to Galsulfase. Orphanet Journal of Rare Diseases 2013; 8(51). http://dx.doi.org/10.1186/1750-1172-8-51

[17] Valayannopoulos V, Nicely $H$, Harmatz P, Turbeville S. Mucopolysaccharidosis VI. Orphaned Journal of Rare Diseases 2010; 5(5): 1-20.

[18] Mabe P. Las Mucopolisacaridosis [Versión electrónica], Revista chilena de nutrición 2004; 31(1): 8-16. http://dx.doi.org/10.4067/S0717-75182004000100001

[19] Tessitore A, Pirozzi M, Auricchio A. Abnormal autophagy, ubiquitination, inflammation and apoptosis are dependent upon lysosomal storage and are useful biomarkers of Mucopolysaccharidosis VI. PathoGenetics 2009; 2(4): 1-12. http://dx.doi.org/10.1186/1755-8417-2-4
[20] Gagliardi C, Bunnell B. Large Animal Models of Neurological Disorders for Gene Therapy. ILAR Journal 2009; 50(2): 128143. http://dx.doi.org/10.1093/ilar.50.2.128

[21] Scarpa M, et al. Mucopolysaccharidosis type II: European recommendations for the diagnosis and multidisciplinary management of a rare disease. Orphanet Journal of Rare Diseases 2011; 6(72). http://dx.doi.org/10.1186/1750-1172-6-72

[22] Federación Colombiana de Enfermedades Raras. Enfermedad rara en Colombia 2012. Available from: http://www.fecoer.org/ enfermedad-rara-en-colombia/

[23] Hernández R, Fernández C, Baptista P.). Metodología de la investigación 2006. México: Mc Graw Hill.

[24] Matute E, Roselli M, Ardila A, Ostrosky-Solís F.). Evaluación Neuropsicológica Infantil (ENI) 2007. Manual Moderno. ISBN 970-729-187-7.

[25] Rosselli M, Matute E, Ardila A, Botero V, Tangarife G, Echeverría S, Arbeláez C. Evaluación Neuropsicológica Infantil (ENI): una batería para la evaluación de niños entre 5 y 16 años de edad. Estudio normativo colombiano. Revista de Neurología 2004; 38(8): 720-731.

[26] Ramos-Loyo J, Taracena A, Ramos-Loyo L, Matute E, González-Garrido A. Relación entre el funcionamiento ejecutivo en pruebas neuropsicológicas y en el contexto social en niños con TDAH. Revista Neurología, Neuropsiquiatría y Neurociencias 2011; 11(1): 1-16. ISSN: 0124-1265

[27] Strauss E, Sherman E, Spreen O. A Compendium of Neuropsychological Tests: Administration, Norms, and Commentary 2006. Third Edition. New York: Oxford University Press.

[28] Kaufman A, Kaufman N. K-BIT Test Breve de Inteligencia de Kaufman 2009. Adaptación Española (3a․ Ed.). Madrid, España: TEA Ediciones S.A.

[29] Petit G, Kornreich C, Noel X, Verbanck P, Campanella S. Alcohol-Related Context Modulates Performance of Social Drinkers in a Visual Go/No-Go Task: A Preliminary Assessment of Event-Related Potentials. PLoS ONE 2012; 7(5): e37466.

http://dx.doi.org/10.1371/journal.pone.0037466

[30] Torpey D, Hajcak G, Kim J, Kujawa A, Klein D. Electrocortical and Behavioral Measures of Response Monitoring in Young Children During a Go/No-Go Task. Developmental Psychobiology 2012; 54(2): 139-50. http://dx.doi.org/10.1002/dev.20590

[31] Vuori-Christiansen L, Ortiz N. Adaptación de la prueba de desarrollo mental de Griffiths a la población de Bogotá Reordenación de los ítems. Revista Latinoamericana de Psicología 1974; 6(3): 347-61

[32] Colombian Congress. Act 23 of 1982. Which regulate the copyright and intellectual property. Available from: http://www.unesco.org/culture/natlaws/media/pdf/colombia/co lombia_ley_23_28_01_1982_spa_orof.pdf

[33] Act 1090-060906 2006. Which regulate the exercise of the profession of psychology; it dictated the Code of Ethics and Bioethics. Chapter 7; Articles 49, 50, 51, 52, 55 and 56, which refer to scientific research, intellectual property and publications.

[34] Act 1392 2010. Through which orphan diseases of special interest are recognized and standards aimed at ensuring social protection by the Colombian State to the people suffering from orphan diseases and their caregivers are adopted. Official Journal, to public-legislative branch. Edition 47,758 .

[35] Colombian Congress. Mental Health Act 1616 of 2013. Which regulate the Mental Health in Colombia. 
[36] Giugliani R, et al. Mucopolysaccharidosis I, II and VI: Brief review and guidelines for treatment. Genetics and Molecular Biology 2010; 33(4): 589-604.

http://dx.doi.org/10.1590/S1415-47572010005000093
[37]

Bae Y, Yoon S, Won S, Jin S, Ko A, Kwon E, Ju S, Jin D. Phase I / II clinical trial of enzyme replacement therapy with idursulfase beta in patients with mucopolysaccharidosis II (Hunter Syndrome). Orphaned Journal of Rare Diseases 2013; 8(42): 1-8.

Received on 16-12-2015

Accepted on 06-01-2016

Published on 14-03-2016

DOI: http://dx.doi.org/10.6000/2292-2598.2016.04.01.8

(C) 2016 Castañeda-Ibáñez and Acosta-Barreto; Licensee Lifescience Global.

This is an open access article licensed under the terms of the Creative Commons Attribution Non-Commercial License (http://creativecommons.org/licenses/by-nc/3.0/) which permits unrestricted, non-commercial use, distribution and reproduction in any medium, provided the work is properly cited. 